\title{
Reflexões sobre as pesquisas em TV no Brasil - propostas metodológicas e formas de análise dos telejornais
}

\section{Flávio Antônio Camargo Porcello}

Doutor; Universidade Federal do Rio Grande do Sul

flavioporcello@uol.com.br

\section{Resumo}

A TV completa 65 anos no Brasil em 2015. Muito diferente e mais abrangente do que a pioneira TV Tupi, de São Paulo, em sua primeira transmissão em setembro de 1950, a televisão no Brasil atinge o público em diversas plataformas, suportes e dispositivos. E continua sendo a principal fonte de informação para os brasileiros. Por isso deve ser estudada com atenção e interesse. Este é o foco do presente texto. As formas de análise dos conteúdos informativos transmitidos pela TV devem evoluir e avançar, da mesma forma que as emissoras fazem em relação aos seus públicos e audiências. Faremos uma recuperação histórica e cronológica das fases da TV no país e dos grupos de pesquisas voltados para os estudos na área. A metodologia será estudo de caso, com observação participante. O objetivo é o de construir coletivamente propostas metodológicas que permitam análises dos telejornais de forma precisa e aprofundada.

\section{Palavras-chave}

Televisão. Telejornalismo. Audiência.

O propósito do presente texto é refletir sobre a Televisão que em 2015 está completando 65 anos no Brasil. A TV, e mais especificamente, o telejornalismo, é o objeto das pesquisas cientificas que realizo e a razão pela qual escolhi o tema para esta edição da revista Intexto, comemorativa aos 20 anos do Programa de Pós-Graduação em Comunicação e Informação da Universidade Federal do Rio Grande do Sul - UFRGS. O interesse pela televisão se deve ao que trouxe em minha bagagem intelectual quando ingressei na UFRGS em 2005, pois atuei profissionalmente como repórter, âncora e editor no Brasil e Exterior por mais de 30 anos em 
emissoras de televisão (Globo, SBT, RBSTV, TV Pampa, TVE-RS, além de ter implantado a UNITV TV Universitária de Porto Alegre, em 1998). Também atuo como professor de disciplinas de Telejornalismo no curso de Jornalismo da Faculdade de Biblioteconomia e Comunicação da UFRGS e como professor, pesquisador e orientador no Programa de Pós-Graduação em Comunicação e Informação - PPGCOM. Também fui o primeiro coordenador da Rede de Pesquisadores em Telejornalismo - TELEJOR, atuando hoje apenas como integrante. Mas a escolha do tema não se deve apenas à experiência profissional anterior e nem ao profundo interesse que tenho pelo tema e, sim, pela importância que a televisão exerce nos processos comunicacionais. A TV aberta está presente em 97\% dos domicílios (INSTITUTO..., 2015) e é a principal fonte de informação dos brasileiros. Mais do que isso, influencia diretamente nos processos políticos, na esfera econômica, na implantação de costumes, nos hábitos e na linguagem das pessoas. Hoje a TV está em diversas plataformas e nos mais variados dispositivos e até mesmo nos antigos aparelhos receptores de televisão ainda com imagens em preto e branco. Mais do que em nossas casas, a TV entra em nossas vidas e este é o principal motivo pelo qual se deu essa escolha do tema para o presente texto. A proposta é oferecer questionamentos e provocações, como forma de instigar os pesquisadores a buscar construir coletivamente metodologias que nos ajudem a pesquisar com mais profundidade a televisão. Citaremos os principais modos de análise utilizados em pesquisas cujo objeto principal é o jornalismo de TV, bem como procuraremos enumerar as metodologias mais utilizadas hoje para estudar o telejornalismo brasileiro.

Mas antes de avançar nesta questão e aprofundar os conceitos teóricos dos recentes estudos e pesquisas em televisão é relevante recuperar o passado da TV no Brasil nos últimos 65 anos.

A primeira transmissão no Brasil aconteceu em 17 de setembro de 1950 por iniciativa de Assis Chateaubriand que fundou a TV Tupi, dos Diários e Emissoras Associados. Mas como a TV ainda era novidade no Brasil quem poderia assisti-la já que ninguém tinha aparelhos receptores? Chateaubriand resolveu facilmente a questão: trouxe para o Brasil 200 aparelhos de TV contrabandeados do Paraguai e os espalhou pela área central da cidade de São Paulo para que as pessoas pudessem assistir. E assim começou a TV no Brasil. Nos 65 anos que se seguiram muito mudou mas as concessões públicas para explorar o espaço eletromagnético continuam as mesmas. São como uma rua de mão única, uma espécie de capitanias hereditárias, como um título vitalício: o Governo Federal concede e nem cogita avaliar ou mesmo cancelar a concessão, 
independente do uso que esteja sendo feito dela. E, da mesma forma, os empresários detentores da concessão ficam desobrigados de dar explicações e justificativas para os excessos cometidos em suas emissoras (PORCELLO; VIZEU; MOTA, 2006, p. 154).

O professor e pesquisador Sérgio Mattos tem caracterizado sua produção intelectual pela recuperação histórica da televisão no Brasil. É de autoria dele a divisão deste percurso histórico em sete fases, assim descritas:

A fase elitista (1950-1964), quando o televisor era considerado um luxo ao qual apenas a elite econômica tinha acesso; a fase populista (1964-1975), quando a televisão era considerada um exemplo de modernidade e programas de auditório e de baixo nível tomavam grande parte da programação; a fase do desenvolvimento tecnológico (1975-1985), quando as redes de TV se aperfeiçoaram e começaram a produzir, com maior intensidade e profissionalismo, os seus próprios programas com estímulo de órgãos oficiais, visando, inclusive, a exportação; a fase da transição e expansão internacional (1985-1990), durante a Nova República, quando se intensificam as exportações de programas; a fase da globalização e da TV paga (1990-2000), quando o país busca a modernidade a qualquer custo e a televisão se adapta aos novos rumos da redemocratização; $a$ fase da convergência e da qualidade digital (2000-2010) começa no ano 2000, com a tecnologia apontando para uma interatividade cada vez maior dos veículos de comunicação, principalmente a televisão, com a internet e outras tecnologias da informação. Nessa fase é adotado o sistema de televisão digital do país e iniciada sua implantação até a substituição total do sistema analógico que deve ocorrer até $\mathrm{o}$ ano de 2016 e a fase da portabilidade, mobilidade e interatividade digital (2010-), quando o mercado de comunicação e o modelo de negócio vão se reestruturar definitivamente, devido ao espaço ocupado pelas novas mídias, a exemplo do celular digital. Nessa fase a produção e distribuição de conteúdo serão de fundamental importância para as redes de televisão. (MATTOS, 2010, p. 85-86).

Neste período de seis décadas e meia de existência da televisão no Brasil muito mudou no panorama das comunicações no país e no mundo. Quando a TV Tupi de São Paulo fez a primeira transmissão ao vivo no dia 17 de setembro de 1950, o Brasil vivia o apogeu da Era do Rádio. 0 cinema também vivia fase de grande expansão graças aos recursos tecnológicos que estavam chegando. Assim a televisão teve nos seus primeiros anos de existência a sua linguagem audiovisual fortemente influenciada pelas vozes do rádio e pelos enquadramentos de imagem do cinema. E os conteúdos editoriais das primeiras décadas da TV eram buscados nas paginas dos jornais impressos. Dizia-se: o jornal noticia e a televisão mostra a notícia com imagens para o seu publico telespectador.

Quando a TV chegou ao Brasil, as comunicações entre as pessoas eram feitas por cartas manuscritas ou, em caso de urgência, pelo telégrafo. 
O impacto das inovações tecnológicas sempre foi um desafio para a TV ao longo de seus 65 anos no país. Lembremos alguns: nos anos 50 as ligações telefônicas eram precárias e imprevisíveis devido aos modestos recursos disponíveis e às distancias enormes em um país de proporções continentais. A telefonia celular chegou em 1994.

Vinte anos antes, em 1974, surgia em escala mundial a internet que já operava em caráter mais restrito desde 1969, resultado de pesquisas acadêmicas e militares realizadas nos Estados Unidos. A Arpanet unia através de redes de fibra ótica cientistas de universidades e instituições de pesquisa. A world wide web (www) surgiu em 1991. O site de pesquisas Google foi criado em 1998, aperfeiçoando o que já faziam outros sites de pesquisa como o brasileiro Cadê, por exemplo.

A expansão das redes sociais deu-se de forma muito rápida e abrangente dos anos 90 em diante. Alguém ainda lembra? Os mais jovens nem sabem qual foi a importância da telefoto para a transmissão de fotografias por linha telefônica ou de texto pelo telex. A chegada do videofone foi saudada como a revolução tecnológica perfeita.

Dele derivaram o fax e depois o e-mail, assim como os mais recentes: Msn, Mirk, ICQ, Orkut, Twitter, Facebook, Instagram, Whattsapp, Periscope, entre tantos outros nomes e siglas de aplicativos que poderiam aqui ser citados. Mas é melhor nem tentar fazer isso pois a velocidade com que as novas formas de comunicação chegam tornaria este texto sempre desatualizado. E como saber quantos novos aplicativos já surgiram desde que este texto é redigido até o momento em que está sendo lido? De qualquer forma, essa velocidade intensa e dinâmica dá bem a ideia do que aqui queremos expressar. Ao longo de sua existência a TV precisou enfrentar e superar os desafios trazidos pelas novas e cada vez mais modernas formas de comunicação. Um exemplo? Quem ainda fica sentado na frente de um aparelho convencional de TV esperando para saber de sua cidade, região, país e mundo apenas pelas noticias da edição de um telejornal?

E quem consegue abrir mão da segunda tela, seja celular, smartphone, tablet, notebook ou qualquer outro dispositivo conectado na internet enquanto vê TV?

Toda essa velocidade tecnológica merece uma pausa para reflexão para que possamos enfrentar os desafios. É o que procuraremos fazer agora trazendo a contribuição de pesquisadores que são referencias internacionais no assunto. Afinal, todas essas mudanças afetam diretamente a atividade de comunicação na relação entre as pessoas que vivem em um mundo cada vez mais dominado pela tecnologia. 
As distancias encurtaram, o tempo ficou menor, as exigências maiores e a memória do passado cada vez fica mais distante e apagada.

Darnton (2009) diz que muitos assuntos importantes hoje em dia são resolvidos através da rede mundial de computadores, o que agiliza a comunicação mas não deixa vestígios na memória escrita: "[...] estamos perdendo o registro material da maior parte da comunicação contemporânea." (p. 70). E complementa: "A maior parte dos seres humanos desapareceu no passado sem deixar vestígio algum de sua existência." (p. 78).

O professor norte-americano nos desafia a manter o hábito que desenvolvemos a partir da invenção da imprensa e registrarmos para a posteridade as memórias dos tempos que vivemos. Oportuna a lembrança pois neste ano de 2015 quando muitas referências são feitas aos 65 anos da TV no Brasil quase a totalidade dos registros existentes são extraídos de fotos e noticias de jornais da época. Quase não há imagens e sons daqueles tempos e o mesmo pode ser dar no futuro se os registros de nossa época atual ficarem restritos a fotos feitas pelo celular ou mensagens por email, que estão armazenadas nas nuvens dos provedores de internet.

Outra reflexão importante é trazida pelo pesquisador e linguista francês Patrick Charaudeau (2007) ao dirigir o foco de seu olhar para a comunicação e atividade jornalística em busca da noticia: "Relatar e comentar acontecimentos é uma atividade impregnada de subjetividades." (p. 241). E acrescenta:

Para contar os acontecimentos as mídias selecionam em função de três critérios: tempo, espaço e acidente. Tempo: um acontecimento deve ser convertido o mais depressa possível em noticia; Espaço: antagonismo entre 'aldeia' e 'planeta'; Acidente: 'insólito' que desafia as normas da lógica(...) (CHARAUDEAU, 2007, p. 253).

O pesquisador espanhol Miquel Rodrigo Alsina (2009) diz que é preciso ter muito claro que os meios de comunicação permitem a visibilidade de certas realidades "[...] mas, ao mesmo tempo, não refletem outros.".

Além do mais, no tocante aos fatos sobre os quais focalizam sua atenção, cada dia fica mais evidente que os produtores da informação simplesmente interpretam os fenômenos sociais. Interpretam a realidade social quando a descrevem. Essa construção da realidade é feita com estratégias discursivas que são invisíveis para os olhos do ingênuo leitor. (ALSINA, 2009, p. 290).

Bourdieu (1996) fala nos "óculos" que os jornalistas usam para ver algumas questões e não enxergar outras. Bem como ditam os chamados "fatos-ônibus", aqueles em que todos embarcam e apontam na direção precisa ao afirmar que, como a TV é regulada pelo tempo cada 
vez mais escasso, cada informação que entra ocupa o lugar de outra que não pôde ser dada justamente pela falta de tempo e espaço no noticiário.

Essa sequência de autores, entre tantos que aqui poderiam ser lembrados, serácompletada agora com importantes reflexões de dois mais experientes pensadores em atividade. Foram escolhidos justamente Zygmunt Bauman e Edgar Morin que, com o aprendizado recolhido em suas mais de nove décadas de vida, nos ensinam a cada dia a ter energia e confiança para enfrentar e superar os desafios da vida.

Bauman (2007) fala na "commoditização" das pessoas e diz que a vida "agorista" tende a ser apressada, pois a demora é o "serial killer" das oportunidades. Ele assinala que "a síndrome consumista envolve velocidade, excesso e desperdício.". E observa que "no mundo-líquidomoderno a lentidão indica a morte social.":

Nos dias de hoje, a prática gerencial de provocar uma atmosfera de urgência, ou apresentar um estado de coisas comum como um estado de emergência, é cada vez mais reconhecida como um método bastante eficaz e preferido por muitos executivos, de persuadir os gerenciados a aceitarem placidamente até mesmo as mudanças mais drásticas que atingem no âmago suas ambições e expectativas - ou, na verdade, a sua própria vida. (BAUMAN, 2007, p. 125).

O pesquisador polonês afirma também que:

O consumismo atua para manter a reversão emocional do trabalho e da família. Expostos a um bombardeio contínuo de anúncios graças a uma média diária de três horas de televisão (metade de todo o tempo de lazer), os trabalhadores são persuadidos a "precisar" de mais coisas. Para comprar aquilo de que agora necessitam, precisam de dinheiro. Para ganhar dinheiro aumentam sua jornada de trabalho. Estando fora de casa por tantas horas compensam suas ausências do lar com presentes que custam dinheiro. Materializam o amor. E assim continua o ciclo. (BAUMAN, 2007, p. 153).

Morin (2002a, 2002b, 2002c, 2002d, 2002e, 2002f), autor da série $O$ método, propõe a "reforma do pensamento" como maneira de renovar nossas relações humanas e como forma de fazer a ciência avançar. Ele assinala em seu paradigma da complexidade que "a parte está no todo, o todo está na parte, mas o todo não é a soma das partes.". E resume de uma forma muito simples e extremamente profunda nossas relações humanas a partir da palavra:

A língua vive. As palavras nascem, deslocam-se, enobrecem-se, pervertem-se, degradam-se e morrem. A língua vive como uma grande árvore, cujas raízes encontram-se nas profundezas das vidas social e cerebral e cujos galhos se espalham pela noosfera. (MORIN, 2002d, p. 211).

Entre tantos autores possíveis, entre tantas pessoas que estudam e publicam sobre o tema, entre as infinitas possibilidades de opiniões definitivas que a todo o momento circulam 
pelas redes sociais, porque trazer Bauman e Morin para completar o que antes havia dito Darnton (2009), Charaudeau (2007), Alsina (2009) e Bourdieu (1996)? Claro que muitos outros autores têm contribuições tão ou até mais importantes que as dos citados acima. Mas a escolha tem uma justificativa. Todos os autores que acabamos de ler, especialmente os dois últimos que têm muito mais experiência de vida -, defendem de forma ardorosa e convicta as relações entre as pessoas.

Importantes são as conexões humanas. As relações sociais são a essência de nossas vidas. Só o ser humano é capaz de gestos de extrema bondade ou de profunda maldade com seu semelhante. E a comunicação social tem papel fundamental nisto, para o bem e para o mal. No âmbito da comunicação social, a TV tem um papel único. Claro que em 65 anos no Brasil e um pouco mais em sua escala mundial aquele aparelho que antes centralizava as atenções da família na sala das casas mudou de forma, de tamanho, de suporte e de papel social. Mas, na essência, continua a fazer a mesma coisa: ligando as pessoas. Wolton (1990) define como "laço social". A TV é capaz disso: dar uniformidade ou evidenciar as diferenças, unir ou desunir, aproximar ou distanciar. No caso da TV aberta, ainda hegemônica no país e capaz de atingir $97 \%$ do território brasileiro, o desafio é falar a mesma coisa ao para todos ao mesmo tempo. Wolton já dizia nos anos 90 do século passado que:

Todo mundo assiste à televisão e fala sobre ela. Qual outra atividade é, hoje, tão transversal? Se a televisão não existisse, muita gente sonharia em inventar um instrumento capaz de réu nir todos os públicos. Isso é o que é a unidade teórica da televisão. Sua importância é, portanto, tão grande política como socialmente. (WOLTON, 1990, p. 16).

E, aos 65 anos, ela continua sendo a maior fonte de informação para a população de um país com dimensões continentais como o Brasil.

Pois é disso que nos falam, com toda a energia vibratória de suas longas existências, Bauman e Morin: a força das palavras para aproximar as pessoas em torno das boas causas, dos bons exemplos, da expansão daquilo que de melhor os seres humanos tem. De novo é bom lembrar: importante são as conexões humanas!

Eles não pedem a recusa aos equipamentos modernos que a cada instante aumentam sua presença em nossa vida, mas nos lembram que eles não substituem as pessoas, seus sentimentos e reações humanas. Bauman e Morin viveram as melhores e as piores experiências dos últimos 90 anos, dos horrores das guerras mundiais e catástrofes, a extermínios, perseguições e radicalismos de todos os tipos. Mas também são testemunhas vivas dos 
melhores avanços da ciência. No âmbito da comunicação viram nascer desde o rádio e o cinema, até a TV, a internet e tudo o que de mais moderno o mundo hoje utiliza em termos de equipamentos eletrônicos e de comunicação. Toda a revolução digital também faz parte dos desafios que os dois tiveram que conhecer, precisaram dominar e, hoje, utilizam no cotidiano para fazerem circular socialmente suas ideias e convicções.

É desses exemplos que devemos partir para olhar, entender e estudar a TV aos 65 anos no Brasil. Mais do que assistir, é preciso decifrar seus sentidos, entender seus sons e silêncios, o que a TV diz ou deixa de dizer, o que mostra e o que deixa de mostrar, enfim, compreender e discutir o discurso político da televisão. É esse o desafio que os pesquisadores em telejornalismo chamaram para si. E para isso são necessários minuciosos e detalhados estudos que incluem a colaboração de várias outras áreas, da engenharia à sociologia, e também a capacidade de compreender os sinais verbais e não verbais que constituem a essência da comunicação televisiva.

Vamos trazer aqui um breve panorama dos passos da rede TELEJOR que reúne os pesquisadores em telejornalismo no país e, mais adiante, mostrar as áreas de interesse e atuação dos referidos pesquisadores nas várias instituições onde realizam suas pesquisas.

A Rede de Pesquisadores em Telejornalismo (TELEJOR) foi criada em novembro de 2005 durante o III Encontro Nacional de Pesquisadores em Jornalismo da Associação Brasileira de Pesquisadores em Jornalismo (SBPJor) realizado na Universidade Federal de Santa Catarina (UFSC). No ano seguinte, 2006, na Universidade Federal do Rio Grande do Sul (UFRGS) foi lançado o primeiro dos sete livros até agora produzidos pela rede: Telejornalismo: a nova praça pública (PORCELLO; VIZEU; MOTA, 2006). Na sequência vieram as seguintes coletâneas, organizadas por Flávio Porcello, Alfredo Vizeu e Iluska Coutinho: A Sociedade do Telejornalismo (VIZEU, 2008); 40 anos de telejornalismo em rede nacional: Olhares críticos (PORCELLO; VIZEU; COUTINHO, 2009); 60 anos de telejornalismo no Brasil: História, análise e critica (PORCELLO; VIZEU; COUTINHO, 2010). Em 2011 a rede TELEJOR concluiu que, em vista do avanço nas pesquisas e da necessidade de compartilhar os resultados com professores, alunos e outros pesquisadores seria importante criar a Coleção Jornalismo Audiovisual que já publicou três volumes: o primeiro, O Brasil (é)ditado (PORCELLO; VIZEU; COUTINHO, 2012); o segundo, \#telejornalismo: nas ruas e nas telas (PORCELLO; VIZEU; COUTINHO, 2013), e o terceiro, Telejornalismo em questão (VIZEU et al., 2014), também organizado por Edna Mello, coordenadora da rede a partir de 2014. 
Além disso, a rede TELEJOR está presente em todos os congressos científicos da área desde sua fundação, com a apresentação de trabalhos e publicações de artigos em encontros nacionais e internacionais. O histórico da rede na última década está reunido no artigo 'Desafios, limites e possibilidades da Rede de Pesquisadores em Telejornalismo' publicado na revista científica Brazilian Journalism Research (PORCELLO, 2011).

Outros grupos de pesquisa com abrangência regional ou nacional existem e são bastante ativos em produções científicas sobre telejornalismo. Entre eles é possível destacar o Grupo Interinstitucional de Pesquisa em Telejornalismo (GIPTELE) que é liderado pelo PPG em Jornalismo da Universidade Federal de Santa Catarina (UFSC) e agrega importantes instituições de pesquisa ligadas a universidades públicas e privadas dos estados do Rio Grande do Sul e Santa Catarina (EMERIM, 2011). O Grupo de Pesquisa em Análise de Telejornalismo (GPAT) do PPG em Comunicação e Cultura Contemporânea da Universidade Federal da Bahia (UFBA) que também reúne pesquisadores de instituições públicas e privadas de várias regiões do Brasil. (GOMES, 2011, 2012; GUTMANN, 2014).

É importante citar também os grupos de pesquisa ligados ao PPG em Comunicação da Universidade Federal de Pernambuco (UFPE) são o GP Jornalismo e Contemporaneidade que conta com a participação dos professores pesquisadores Alfredo Vizeu e Heitor Rocha e o GP Mídia e Cultura Contemporânea (UFPE e Universidade Católica de Pernambuco) com as professoras pesquisadoras Yvana Fechine e Luisa Carvalho Abreu e Lima (VIZEU, 2015; FECHINE, 2008; FECHINE; CARLÓN, 2014).

Vizeu (2008) criou o conceito de Audiência Presumida, partindo do conceito de Contrato de Comunicação de Charaudeau e aplicando em sua observação presencial sobre as rotinas produtivas dos jornalistas da redação da TV Globo no Rio de Janeiro. O conceito analisa e interpreta o que o jornalista pensa sobre o que o telespectador está esperando receber na matéria de TV. Ou seja, o jornalista imagina que esse ou aquele enfoque vai interessar mais ao telespectador ansioso pela noticia. E isso influencia diretamente o profissional ao adotar seus critérios de escolha na produção, realização e edição de matérias jornalísticas para a TV. Ver mais em O lado oculto do telejornalismo (VIZEU, 2005) onde está a tese de doutoramento de Alfredo Eurico Vizeu Pereira Junior sobre o tema.

Em Minas Gerais, as professoras pesquisadoras Iluska Coutinho, Christina Musse, Paulo Roberto Figueira Leal e Potiguara Mendes Silveira Junior, entre outros, coordenam importantes Grupos de Pesquisa ligados ao PPG em Comunicação da Faculdade de Comunicação (FACOM) da 
Universidade Federal de Juiz de Fora (UFJF) com produtivas pesquisas e intensa produção científica sobre Telejornalismo e Memória (COUTINHO, 2012, 2013; MUSSE, 2012). Das pesquisas deste GP já vieram importantes contribuições como a dissertação de mestrado de Jhonatan Mata que resultou no livro Um telejornal para chamar de seu (MATA, 2013).

Coutinho criou o método que permite estudar o telejornalismo a partir das narrativas dramatúrgicas que ele utiliza. A TV usa em seu discurso a linguagem dramática para atrair e prender a atenção do telespectador. Os recursos utilizados no telejornalismo obedecem a uma lógica diversa das narrativas dos programas de ficção ou mesmo das telenovelas nas quais os roteiros são produzidos a partir da imaginação criativa dos diretores. No telejornalismo trabalhase com fatos reais mas há sensível influência dos tons dramáticos nas narrativas factuais. Ou seja, não se pode mudar a história mas é possível contá-la com acentuados tons de dramaticidade. A tese de doutoramento de Coutinho está apresentada no livro Dramaturgia do telejornalismo brasileiro (COUTINHO, 2012). Já Musse (2012) trabalha com a importância do jornalismo como produtor de memória visto que as notícias de hoje serão no futuro a memória e os registros do passado. Ela defende a preservação dos arquivos especialmente do telejornalismo já que a evolução constante nas formas de captação e registro de imagens pela TV dificulta a guarda destes registros nos arquivos das emissoras.

Na região sul do Brasil o Grupo GIP Tele propõe uma articulação teórica: as pesquisas sobre telejornalismo são desenvolvidas a partir do marco teórico da narrativa e da midiatização. No entanto, do ponto de vista da teoria da narrativa, não são mobilizadas apenas as perspectivas teóricas clássicas apresentadas pelos autores estruturalistas, enquanto pioneiros na sistematização das pesquisas sobre a arte de contar boas histórias. Neste sentido, articula-se a teoria da narrativa levando em conta o diálogo com autores que dão conta das representações de real no contemporâneo, especialmente preocupados com as implicações sócio-técnicas e estéticas geradas pelas práticas narrativas advindas de novos padrões tecnológicos. Dessa forma, une-se a estas investigações o esforço teórico oportunizado pela midiatização que estuda a narrativa advinda e oriunda de natureza midiática, tomando o contexto o contemporâneo como aquele em que as mídias abandonam gradativamente o lugar de suporte aos discursos que até então ocupavam, para ser o próprio lócus de onde emergem os discursos a partir de uma nova ecologia comunicacional. Do ponto de vista teórico-metodológico, o Grupo GIP Tele propõe uma articulação entre as práticas do Jornalismo, as ferramentas da História (na especificidade da pesquisa em História Oral) e a proposta metodológica da análise Semiótica de produtos 
midiáticos, que, assim organizados, puderam propor um objeto eficaz de investigação. A metodologia que vem sendo aplicada pela pesquisadora Cárlida Emerim dentro do Grupo Interinstitucional de Pesquisa em Telejornalismo na UFSC emprega a Semiótica Discursiva considerando a produção, a circulação e o consumo destas produções, mantendo o foco de análise no nível discursivo e reiterando a importância do contexto de produção dos objetos (EMERIM, 2011).

Do mesmo grupo GIP Tele, o pesquisador Antônio Brasil, também da UFSC, propõe novas abordagens para a produção e ensino de jornalismo para TV na era digital. A convergência de mídias completa novo ciclo digital e finalmente permite a inclusão do meio televisivo e seu segmento noticioso, o telejornalismo, na Internet. Os estudos se inserem no contexto das "pesquisas aplicadas" ou "pesquisa-ação" nas áreas da Comunicação, Jornalismo e Novas Tecnologias. É uma evolução de pesquisas anteriores de doutorado e pós-doutorado realizadas na Universidade Federal do Rio de Janeiro, Universidade do Estado de Nova Jersey, na Rutgers University nos EUA e na Universidade Sorbonne Nouvelle, Paris 2, França nos últimos 15 anos. 0 resultado foi a criação e desenvolvimento de produções telejornalísticas como a TV UERJ online, a primeira TV universitária brasileira na Internet em 2001 e o TJ UFSC, o telejornal diário da Universidade Federal de Santa Catarina em 2011: "O objetivo de nossas pesquisas tem sido analisar, experimentar e desenvolver novos modelos de programas televisuais e telejornais interativos para os meios digitais.". A hipótese é de que o acesso às novas tecnologias oferece oportunidades para o desenvolvimento de linguagens e formatos interativos voltados para a produção jornalística, para o aprimoramento do ensino de telejornalismo na era digital e democratização dos telejornais nas televisões e nas redes telemáticas. (BRASIL, 2012).

No Rio Grande do Sul, em Porto Alegre, o Grupo de Pesquisa Televisão e Audiência (GPTV) reúne professores pesquisadores e alunos de mestrado e doutorado da Universidade Federal do Rio Grande do Sul (UFRGS) e da Pontifícia Universidade Católica do Rio Grande do Sul (PUCRS). O desafio proposto pelo grupo é avaliar o impacto do nosso contexto de convergência digital sobre a televisão. A intenção é a de mapear o público - heterogêneo e nômade - que assiste TV seja em que plataforma ou dispositivo for, até mesmo o tradicional aparelho receptor de televisão. Como formas de chegar ao objetivo proposto a ideia que une os pesquisadores do grupo é aprofundar as discussões sobre as rotinas de produção, as estratégias narrativas funcionais ou jornalísticas e as mudanças de comportamento das audiências neste novo contexto. Pretende-se realizar pesquisas aplicadas, proposição de novas metodologias de analise e desenvolvimento de 
projetos que aproximem ensino e pesquisa com o propósito de compartilhar os resultados em publicações e eventos científicos da área, como o presente texto.

Finger direciona suas pesquisas para a utilização de outros recursos paralelos por onde a televisão também opera. Por ela chamados de 'segunda tela', os outros dispositivos móveis são acionados em concorrência direta e inevitável com a TV que precisa adaptar-se e reposicionar suas narrativas alterando o modo convencional pelo qual atuou nas primeiras décadas de sua existência, soberana no discurso audiovisual.

Porcello (2006) trabalha com Hermenêutica de Profundidade (HP) de John Thompson, com a interpretação e reinterpretação de dados. A metodologia considera que a televisão dá prioridade ao componente visual de maneira a causar muita fascinação ao público.Ela aumenta o peso da imagem em relação ao valor da palavra. E o telespectador decodifica mais facilmente os códigos visuais do que os sonoros. "Se alguém diz: isso apareceu na TV! O outro aceita a situação como real. Se apareceu na TV então aconteceu!" (PORCELLO, 2006, p. 146).

Mas a TV não é mera observadora dos fatos. Por trás de uma câmera está o olhar de um cinegrafista; a matéria é uma história contada pela ótica do repórter; na edição o jornalista faz escolhas, optando por uma e não por outra cena, por esse e não por aquele trecho da resposta do entrevistado. TV é edição, é recorte, é escolha, é fragmento. O desafio de quem trabalha nela é escolher certo, com responsabilidade, critério, ética, e, principalmente, honestidade. Existe imparcialidade jornalística? É claro que não. A ótica do jornalista, do cinegrafista, do fotógrafo, do editor, do chefe da redação, do diretor da empresa, e dos interesses que ele representa, sempre estarão de algum lado. (PORCELLO; VIZEU; MOTA; 2006, p. 146).

A tese de doutoramento de Porcello (2004) sobre o papel da TV na disputa entre Lula e Serra nas eleições presidenciais de 2002 utilizou o método Dialético Histórico-Estrutural (DHE) de John Thompson em conjunto com a teoria da Semiologia de Barthes. Ela encontra-se resumidamente apresentada no capítulo TV e Poder: as relações sombrias que ajudam a fazer a história recente do Brasil publicada no livro Telejornalismo: A nova praça pública (PORCELLO; VIZEU; MOTA, 2006).

Em 2015, no décimo Encontro Nacional de História da Mídia (ALCAR) realizado na Fabico/UFRGS, foi apresentado no GT História da Mídia Audiovisual e Visual o trabalho que propôs justamente a valorização dos arquivos de emissoras de TV como forma de preservação da memória social (PORCELLO; IHITZ; PEIXOTO, no prelo).

Esse é um dos aspectos que não pode ser desconsiderado quando se trata dos 65 anos de TV no Brasil. Muito da memória deste período foi perdido ou apagado. Para que o erro não se 
repita no futuro é fundamental insistir nos cuidados essenciais para que os registros jornalísticos de hoje sejam preservados para consultas futuras. Mas agora é preciso avançar no tema proposto para o presente texto: os vários percursos metodológicos seguidos pelos pesquisadores de vários pontos do país anteriormente citados nos estimulam a pensar numa metodologia própria para os estudos em telejornalismo.

\begin{abstract}
A TV pode ser vista por dois olhares: o da pesquisa acadêmica e o da atuação profissional, onde enquadra-se o telejornalismo, objeto desta análise. Sabe-se que as duas esferas - academia e mercado de trabalho - operam em velocidades diferentes. Mas é preciso provocar a aproximação. Uma mídia ágil como a TV tem pressa, mas mesmo respeitando seu ritmo veloz precisa ser mais cuidadosa e conhecedora das questões acadêmicas. O meio acadêmico, por sua vez, é lento pela natureza dos processos de pesquisa, mas precisa ter mais compromisso social. A TV deve respeitar os preceitos da ciência. E os cientistas devem compartilhar seu conhecimento com a sociedade que os financia. A pesquisa precisa ser aplicada para gerar benefícios em todas as áreas do conhecimento $E$ para que esse objetivo seja alcançado o veículo perfeito é a televisão por sua abrangência e alcance social. (SOSTER; TONUS, 2015, p. 61).
\end{abstract}

A televisão tem suas peculiaridades próprias e, dentro dela, o telejornalismo também está a exigir uma metodologia própria que contemple suas especificidades. Naturalmente devemos considerar que são muito válidas as contribuições de outras áreas, de dentro e de fora do campo da Comunicação e das Ciências Sociais Aplicadas. Mas é preciso avançar. Faremos aqui uma proposição inicial para suscitar o debate de ideias e estimular a discussão acerca do tema.

O telejornalismo aproxima muito teoria e prática. Em geral o objeto de pesquisa está em movimento e é dinâmico como a TV com sua sequência rápida e trepidante de imagens conjugadas com sons. Texto e imagem em TV estão ajustados de forma a não competiram entre si e, sim, atuarem de forma conjugada facilitando a compreensão da informação pelo público. Para entender o conteúdo da mensagem televisiva é preciso juntar essas mídias, mas para estudar o conteúdo da TV talvez seja preciso separá-las. Assim como na produção de conteúdos jornalísticos se usa, com critérios de edição bem definidos, a combinação entre imagem e texto, igual critério pode ser usado na análise de objetos de pesquisa decorrentes de produtos televisivos. Isto é: separa-se o texto para analisar o conteúdo das palavras, a linguagem verbal; separa-se a imagem para analisar a linguagem não verbal; e, analisados separadamente, texto e imagem poderão permitir conclusões mais precisas sobre a linguagem audiovisual da TV.

É um caminho que precisa ser melhor definido e discutido pelos grupos de trabalho que reúnem pesquisadores da área. Esse método pode funcionar muito bem na análise de matérias 
jornalísticas por exemplo. Mas será que funciona com entrevistas sonoras? Ou com imagens que não vêm acompanhadas de texto e sim de fundo musical como clipes ou com som ambiente, como manifestações de protesto, conflitos bélicos ou torcidas de futebol? São apenas exemplos que podem e devem ser melhor desenvolvidos e aprofundados, construindo coletivamente uma proposta de análise.

A ideia aqui é a de provocar essa discussão e estimular o debate.

Em televisão trabalha-se em equipe. Não é possível fazer televisão se não for uma construção coletiva. Ninguém trabalha sozinho em TV. A pesquisa cientifica é, por sua característica, um trabalho mais individualizado. E a produção de textos é, sempre, missão solitária de quem está escrevendo. O pesquisador e suas ideias. Ele e o silêncio da intimidade com seu texto.

Gostaria de propor aqui o debate mais aberto entre as dezenas de pesquisadores que tanta contribuição produtiva trazem sobre os estudos em TV. A rede TELEJOR, assim como os outros grupos de pesquisa que atuam no país, já fazemos isso. Mas ainda é pouco, precisamos avançar. Congressos, seminários, encontros, enfim, oportunidades de debates entre os pesquisadores são frequentes e constantes. Mas é preciso fazer mais. A proposta final deste texto é a de, humildemente, colocar o autor à disposição de todos que quiserem participar, debater, discutir e avançar. $\mathrm{O}$ objetivo é criarmos uma régua ou sistema de participação colaborativa que nos permita adotar critérios claros e precisos para ver a TV com olhos de pesquisador, enxergando de forma clara e precisa o que ela mostra com suas imagens e sons e o que deixa de mostrar com seu silêncio. É preciso apurar o olhar, aguçar os ouvidos, ver e enxergar melhor o que a TV diz e faz! Vamos avançar! É o nosso compromisso!

\section{Referências}

ALSINA, Miquel Rodrigo. A construção da notícia. Petrópolis: Vozes, 2009.

BAUMAN, Zygmund. Vida para consumo. Rio de Janeiro: Zahar, 2007.

BOURDIEU, Pierre. Sobre a televisão. Rio de Janeiro: Zahar, 1996.

BRASIL, Antônio. Telejornalismo imaginário. Florianópolis: Insular, 2012.

CHARAUDEAU, Patrick. O discurso das mídias. São Paulo: Contexto, 2007. 
COUTINHO, Iluska. Dramaturgia do telejornalismo brasileiro: a estrutura narrativa da informação em rede e nas emissoras de televisão em Juiz de Fora. Rio de Janeiro: Mauad, 2012.

COUTINHO, Iluska (Org). A informação na TV Pública. Florianópolis: Insular, 2013.

DARNTON, Robert. A questão dos livros. São Paulo: Companhia das Letras, 2009.

EMERIM, Cárlida (Org.). Pesquisa em telejornalismo: resultados e experiências. Novo Hamburgo: FEEVALE, 2011.

FECHINE, Yvana. Televisão e presença: uma abordagem semiótica da transmissão direta. São Paulo: Estação das Letras e Cores, 2008.

FECHINE, Yvana; CARLÓN, Mário (Orgs). O fim da televisão. Rio de Janeiro: Confraria dos Ventos, 2014.

GOMES, Itania Maria Mota (Org). Gêneros televisivos e modos de endereçamento no telejornalismo. Salvador: EDUFBA, 2011.

GOMES, Itania Maria Mota (Org). Análise de telejornalismo: desafios teórico-metodológicos. Salvador: EDUFBA, 2012.

GUTMANN, Juliana Freire. Formas do telejornal: linguagem televisiva, jornalismo e mediações culturais. Salvador: EDUFBA, 2014.

INSTITUTO BRASILEIRO DE GEOGRAFIA E ESTATÍSTICA - IBGE. Pesquisa nacional por amostra de domicílios: acesso à internet e à televisão e posse do telefone móvel celular para uso pessoal: 2013. Rio de Janeiro: IBGE, 2015. Disponível em:

<http://biblioteca.ibge.gov.br/visualizacao/livros/liv93373.pdf>. Acesso em: 30 abr. 2015.

MATA, Jhonatan. Um telejornal para chamar de seu: identidade, representação e inserção popular no telejornalismo local. Florianópolis: Insular, 2013.

MATTOS, Sérgio. História da televisão brasileira: uma visão econômica, social e política. 5. Ed. Petrópolis: Vozes, 2010.

MORIN, Edgar. 0 método 1: a natureza da natureza. Porto Alegre: Sulina, 2002a.

MORIN, Edgar. 0 método 2: a vida da vida. Porto Alegre: Sulina, 2002b.

MORIN, Edgar. 0 método 3: a vida da vida. Porto Alegre: Sulina, 2002c.

MORIN, Edgar. O método 4: o conhecimento do conhecimento. Porto Alegre: Sulina, 2002d.

MORIN, Edgar. 0 método 5: a humanidade da humanidade. Porto Alegre: Sulina, 2002e.

MORIN, Edgar. O método 6: a ética. Porto Alegre: Sulina, $2002 f$. 
MUSSE, Christina Ferraz. Memórias possíveis: personagens da televisão em Juiz de Fora. São Paulo: Nankin; Juiz de Fora: Funalfa, 2012.

PORCELLO, Flávio. Mídia e poder: o que esconde o brilho luminoso da tela da TV?. Revista FAMECOS, Porto Alegre, v. 31, p. 79-84, 2006.

PORCELLO, Flávio. Comunicação, TV e poder no Brasil: fait divers, discurso e ideosfera - um olhar sobre as eleições de 2002. 2004. Tese (Doutorado em Comunicação Social) - Pontifícia Universidade Católica do Rio Grande do Sul, Porto Alegre, 2004.

PORCELLO, Flávio Antônio Camargo. Desafios, limites e possibilidades da Rede de Pesquisadores em Telejornalismo. Brazilian Journalism Research, Brasília, v. 7, n. 2, p. 47-53, 2011. Disponível em: <http://bjr.sbpjor.org.br/bjr/article/view/337/311>. Acesso em: 30 set. 2015.

PORCELLO, Flávio; IHITZ, Greetchen Ferreira; PEIXOTO, Filipe. Arquivos do telejornalismo: a memória fragmentada dos 65 anos de TV no Brasil. In: ENCONTRO NACIONAL DE HISTÓRIA DA MÍDIA, 10., 2015, Porto Alegre. No prelo.

PORCELLO, Flávio; VIZEU, Alfredo; MOTA, Célia Ladeira (Orgs.). Telejornalismo: a nova praça pública. Florianópolis: Insular, 2006.

PORCELLO, Flávio; VIZEU, Alfredo; COUTINHO, Iluska (Orgs.). 40 anos de telejornalismo em rede nacional: olhares críticos. Florianópolis: Insular, 2009.

PORCELLO, Flávio; VIZEU, Alfredo; COUTINHO, Iluska (Orgs.). 60 anos de telejornalismo no Brasil: história, análise e crítica. Florianópolis: Insular, 2010.

PORCELLO, Flávio; VIZEU, Alfredo; COUTINHO, Iluska (Orgs.). O Brasil (é)ditado. Florianópolis: Insular, 2012. (Coleção Jornalismo Audiovisual ; v. 1)

PORCELLO, Flávio; VIZEU, Alfredo; COUTINHO, Iluska (Orgs.). \#telejornalismo: nas ruas e nas telas. Florianópolis: Insular, 2013. (Coleção Jornalismo Audiovisual ; v. 2)

SOSTER, Demétrio; TONUS, Mirna (Orgs.). Jornalismo-Laboratório: televisão. Santa Cruz do Sul: EDUNISC, 2015.

VIZEU, Alfredo (Org.). A sociedade do telejornalismo. Petrópolis: Vozes, 2008.

VIZEU, Alfredo (Org.). Decidindo o que é notícia. 2. ed. Porto Alegre: EdiPUCRS, 2015.

VIZEU, Alfredo (Org.). O lado oculto do telejornalismo. Salvador: Calandra, 2005.

VIZEU, Alfredo et al. (Orgs.). Telejornalismo em questão. Florianópolis: Insular, 2014. (Coleção Jornalismo Audiovisual ; v. 3)

WOLTON, Dominique. O elogio do grande público. São Paulo: Ática, 1990. 


\title{
Reflections on research on TV in Brazil - methodological proposals and forms of analysis of TV news
}

\begin{abstract}
In 2015, the TV completes six and a half decades of transmissions in Brazil. Very different and much broader than the TV Tupi of São Paulo, in its firsts broadcasts in September 1950, the television in Brazil today reaches audiences across platforms, media and devices. And it remains being the main source of information for the Brazilian population. Hence, it must be studied with attention and interest by researches in the area of Communication. This is precisely the main focus of this article, we understand that the forms of analysis of the informative content transmitted by TV must evolve and advance in the same way in which the broadcasters evolve in relation to their public and audiences. We will make a historical and chronological recovery of the phases o television in Brazil and of the brazilian research groups focused on studies on the journalism of the TV news. We believe it is possible to collectively construct methodological proposals to analyze TV news programs in depth and with precision.
\end{abstract}

\section{Key-words}

Television. TV news. Audience.

Recebido em 31/08/2015

Aceito em 03/11/2015 